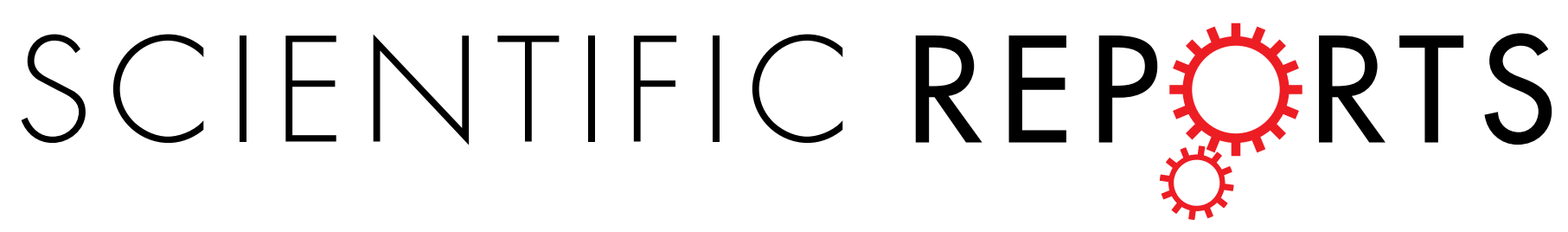

OPEN Author Correction: Repetitive

Published online: 07 September 2018

\title{
transcranial magnetic stimulation reveals a causal role of the human precuneus in spatial updating
}

Notger G. Müller, Martin Riemer, Lisa Brandt \& Thomas Wolbers

Correction to: Scientific Reports https://doi.org/10.1038/s41598-018-28487-7, published online 05 July 2018

This Article contains errors in Figure 1. The labelling in panel d is incorrect and panel e was omitted. The correct Figure 1 appears below. 
a)
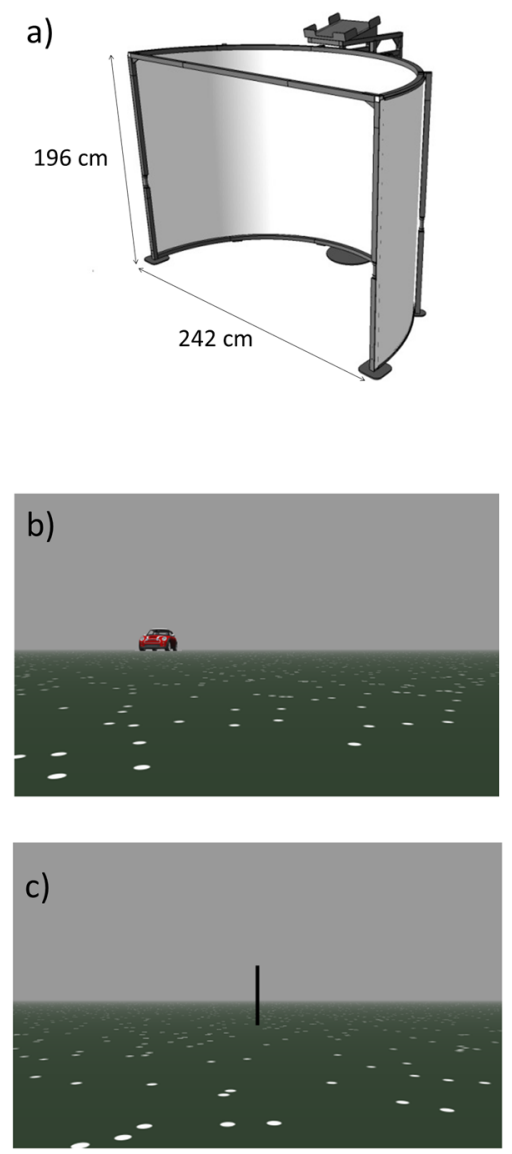

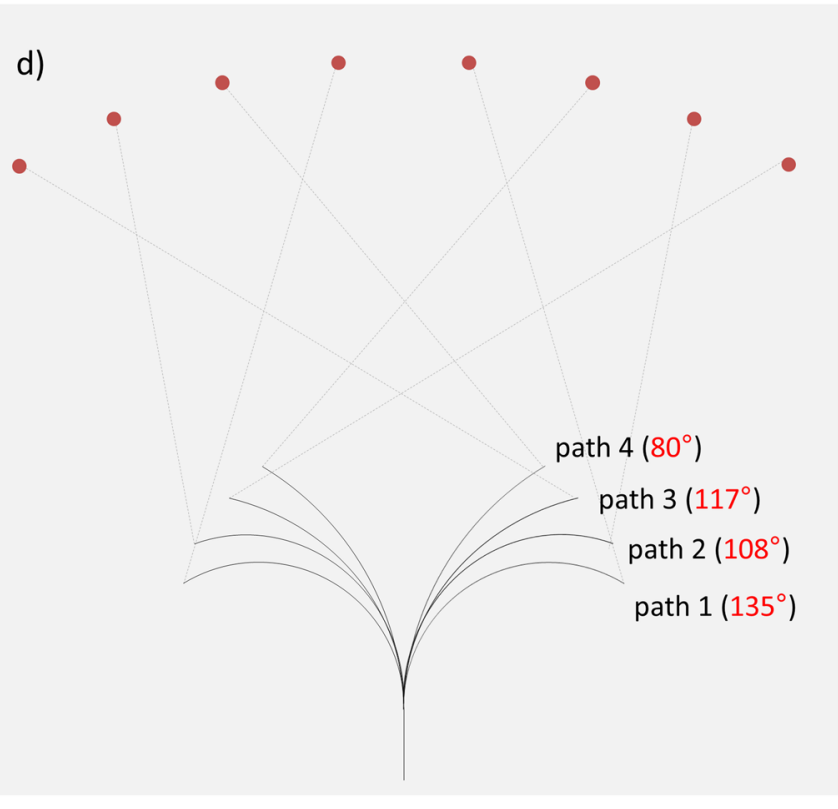

e)

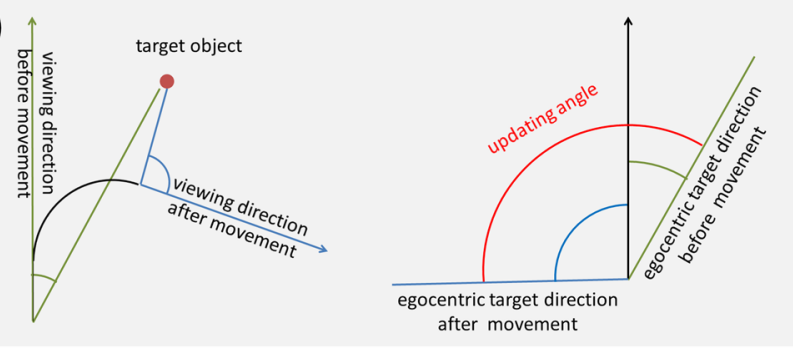

Figure 1. Experimental setup. (a) Circular screen used for the presentation of the virtual environment as shown in (b) and (c). (d) Schematic depiction of the eight different paths and their respective target locations. Numbers in red denote the updating angle associated with each path-target combination. (e) Updating angle was quantified by the angular difference of the egocentric direction towards the target object before (green angle) and after passive movement (blue angle). Copyright Information: (a) was provided for this publication by the manufacturer of the c-screen (Arene Tech, Strassbourg, France). (b,c) are screenshots from the actual experiment. (d,e) was drawn by one of the authors (MR).

(i) Open Access This article is licensed under a Creative Commons Attribution 4.0 International License, which permits use, sharing, adaptation, distribution and reproduction in any medium or format, as long as you give appropriate credit to the original author(s) and the source, provide a link to the Creative Commons license, and indicate if changes were made. The images or other third party material in this article are included in the article's Creative Commons license, unless indicated otherwise in a credit line to the material. If material is not included in the article's Creative Commons license and your intended use is not permitted by statutory regulation or exceeds the permitted use, you will need to obtain permission directly from the copyright holder. To view a copy of this license, visit http://creativecommons.org/licenses/by/4.0/.

(C) The Author(s) 2018 